\title{
Social-cognitive Factors in Health Behavior Change
}

\section{Britta Renner}

\section{Ernst-Moritz-Arndt Universität Greifswald}

and

\section{Ralf Schwarzer}

\section{Freie Universität Berlin}

\section{Introduction}

Konstanzer Online-Publikations-System (KOPS) URL: http://www.ub.uni-konstanz.de/kops/volltexte/2008/7164/ URN: http://nbn-resolving.de/urn:nbn:de:bsz:352-opus-71648

Risk communication and resource communication are two basic approaches to motivate health behavior change. Risk information, as provided in the media, is more complex than it appears. A ratio or percentage is usually based on a selected time window, a specific population, exposure rates, etc. that are hard to communicate and even harder to understand. Single exposure and cumulative exposure over various time periods result in different risk estimates. Joint exposure to a number of risks might involve synergistic effects that an individual cannot grasp. Thus, misjudging given risk information is normal, whereas the accurate understanding of risks is the exception. Moreover, even when a risk for a certain population or reference group is well understood, this does not imply that the individual would believe him or herself to be personally at risk. Defensive optimism moves people away from reality and inhibits them from preventive action. Since risk perception sets the stage for health protection motivation, it is essential to learn more about these mechanisms.

The present chapter describes risk perception biases and other variables and processes that have been found pertinent in the adoption and maintenance of health behaviors. First, one section deals with various reasons why published risk data are not accurately perceived by the public. Another section examines the optimistic bias, a particular distortion to serve self-enhancement when it comes to face severe health threats. Second, two further sections distinguish between continuum models and stage models of health behavior change. One 
such model, the Health Action Process Approach, is based on the assumption that there are at least two distinct phases, one that leads to a behavioral intention and another that leads to actual health behavior. Within both phases, different patterns of social-cognitive predictors may emerge, with perceived self-efficacy as the only one that remains a stable predictor. It is argued that, in designing interventions, one needs to identify whether people are preintentional or post-intentional before tailoring interventions to different target groups. Resource communication is seen as essential when people have set themselves a goal to change their lives, whereas risk communication is regarded as part of an early stage intervention when people are not yet motivated to set a particular goal.

\section{Misjudging Risk Information}

Many health conditions are caused by risk behaviors such as problem drinking, substance abuse, smoking, reckless driving, overeating, or unprotected sexual intercourse. Fortunately, human beings have, in principle, control over their conduct. Health-compromising behaviors can be eliminated by self-regulatory interventions, and health-enhancing behaviors such as physical exercise, smoking cessation, weight control, preventive nutrition, dental hygiene, condom use, or accident precautions, can be adopted instead. Given that most preventable diseases are rooted in lifestyle factors, health professionals are concerned with changing health risk behavior through interventions.

A necessary first step in changing health behavior is to become aware of the connections between behavior and health. Motivating people to engage in preventive nutrition demands that, for example, they are made aware of the role of dietary-intake in health. Therefore, most intervention programs provide information about health risks and hazards to improve knowledge about causes of health and illness. Since the late 1970s, for instance, numerous public health campaigns have focused on cardiovascular disease risk factors in order to inform the public about preventive behaviors. Frank et al. (1993) reported that between 1979 and 1990 general knowledge about what a person can do to keep from having a heart attack or a stroke improved significantly. Especially, cholesterol-related knowledge showed particularly marked improvements (see also Fortmann et al., 1993). This and other studies, such as the Pawtucket Heart Health Program (Niknian et al., 1991), support the notion that moving individuals from the stage of being unaware that a threat exists, to acknowledging a threat, is a necessary first step in the process of changing health behavior.

It is certainly advantageous for the message to come from someone who is perceived as a trustworthy expert (Siegrist and Cvetkovich, 2000). However, the general question - how do we change individuals' health behaviors? - is not satisfactorily answered merely by making information available. This does not by itself allow people to make informed judgments and decisions because information can be easily misinterpreted. This is particularly apparent in the way that laypersons process health risk information. 
A significant part of public health campaigns is risk communication, which means increasing knowledge about the nature, magnitude, and significance of health risks. The underlying assumption is that people can only make appropriate decisions about preventive actions if they perceive risk accurately. Information about risks is communicated through a variety of channels such as brochures, pamphlets, newspapers, television, and the World Wide Web. Jimison and Sher (2000) reported that there are more than 40,000 producers of risk information in the United States. In spite of the expanding public information about risks, government officials and scientists often complain about the public's limited ability to evaluate and interpret risk information (Covello, 1992). Factual risk or objective risk is defined by technical experts as annual injury, fatality rates, accident probabilities, or the mean loss of life expectancy. For example, in Western countries, diseases take significantly more lives per year than accidents. Consequently, diseases represent a greater factual risk than accidents. However, Lichtenstein et al. (1978) showed that laypersons believed that accidents caused as many deaths as diseases, whereas in fact, in the United States in the late 1970s, diseases actually took about 16 times as many lives as accidents. In general, laypeople tend to overestimate rare causes of death, while underestimating common causes of death.

The study by Lichtenstein et al. (1978) stimulated numerous experiments devoted to judgmental biases in the processing of risk information (for overviews see Chapman and Elstein, 2000; Slovic et al., 1987; Yates, 1992). These studies showed that both laypersons and health providers do not calculate risk in the same "rational" manner as technical experts to determine the magnitude of risk. In contrast, Schneiderman and Kaplan (1992) demonstrated evidence for irrational behaviors in response to lethal diseases. They reported that health care providers, who are at risk of infection resulting from accidental exposure to blood, such as injury from a hypodermic needle, took only few precautions to prevent a hepatitis B infection, but they took exceptional precautions when treating patients who were HIV infected. In regard to the normative model, one can argue that this is irrational because the probability of death from both diseases is virtually the same (about l percent). However, these diseases differ with respect to the chance of infection following accidental exposure (hepatitis B: 25 percent versus HIV: 1 percent) and the chance of dying once one has become infected (hepatitis B: 5 percent versus HIV: 100 percent). The authors suggest that individuals take more effort to avoid an HIV infection in comparison to hepatitis B infections because they fear the certainty of death, even though the probability of an HIV infection is very low. This study makes it obvious that laypeople calculate the overall risk posed by a certain disease in a different way than risk experts do. Instead of multiplying the chance of infection by the chance of dying, which results in an overall risk of 1 percent for both diseases, people focused their judgments on the lethal consequences, while ignoring the probability of infection.

The phenomenon "fear of certainty of death" described above may apply in the case of HIV infection due to high levels of stress and anxiety, no matter 
how unwarranted, but on the other hand it may also lead to a greater use of protective measures. More alarming for health educators is the fact that the risk of other contagious diseases might be underestimated, since death is not perceived as a certain outcome once one has become infected, which might result in a failure to take necessary precautions. One could further reason that new and more efficient therapies not only lessen suffering, but might also lead to an unwarranted decline in perceived threat and protective behavior. For instance, since 1995, the number of new AIDS cases has declined in most Western countries (Robert Koch Institut, 2000). This is not due to a decline in the newly infected rate, but rather to the treatment of HIV infections with anti-retroviral drugs that considerably delay the onset of AIDS. Some researchers expressed their concern that the more efficient treatments will encourage risk behavior. In line with this assumption, a recent survey in Germany showed that in some sub-populations, protective behavior is in fact decreasing (Bochow, 2000).

For optimizing health promotion efforts, it is especially important to understand how individuals construe the risk of a certain health threat. According to most current theories of health behavior, risk perception has two aspects: perceived severity of a health condition, and personal vulnerability toward it. The first refers to the amount of harm that could occur, and the second pertains to the subjective probability that one could fall victim to that condition.

Theoretically, the relationship of these two variables has been described by a simple probability by severity interaction, which can be understood as a "normative" or "rational" principle. This means, for instance, that if the personal vulnerability or likelihood of the event is zero, the resulting perceived risk should also be zero, regardless of how serious the event may be.

Conversely, Weinstein (2000) has demonstrated that interest in obtaining protection is not always a function of severity and likelihood. The type of the relationship among severity, likelihood, and motivation to act varied with the severity and likelihood of the hazard. For serious, low-probability events, an interaction could be observed which represents this assumed synergism between the two variables. In contrast, individuals showed insensitivity to variations in likelihood once likelihood had reached the threshold of a 50-50 chance.

Weinstein (2000) suggests that people make finer distinctions at the low end of the likelihood scale than at the high end. Therefore, individuals confronted with a hazard with a 50 percent chance of occurring may display the same reaction as individuals who are confronted with a hazard with an 80 percent chance of occurring. This could explain why, for instance, many individuals view smoking and high cholesterol as cardiovascular risk factors of similar magnitude, although smoking is far more dangerous. Therefore, risk communication must supply information about the relative risks of acquiring one disease versus another to help people anchor the likelihood of occurrence and severity in appropriate ways. Otherwise, individuals may ignore considerable differences and consequently fail to take appropriate measures to protect themselves.

One could reasonably argue that the discrepancy between actual responses and those advocated by normative models or risk experts is not necessarily 
indicative for human irrationality, since laypeople may just have another, albeit consistent, view about risk. Slovic et al. (1987) demonstrated that laypeople's judgments of risk are sensitive, for example, to the controllability of the risk, its familiarity, and its catastrophic potential, as well as to the length of time before severe consequences will emerge. However, recent studies show more straightforwardly that laypeople not only use other conceptions about risk than experts, but that they also show clear inconsistencies and misconceptions about risk.

Many risks have a relatively low probability for any single exposure. However, these small probabilities add up over repeated exposures to create a substantial overall risk. Even if people are accurately aware that a certain behavior increases the risk of becoming ill, and that risk increases with greater exposure, they fail to apply appropriate rules when estimating the danger of increasing exposure to certain risks. For example, Sastre et al. (1999) asked 155 French adults to estimate the risk of developing lung cancer for certain smoking habits. They found that all participants, smokers as well as nonsmokers, believed that the risk of lung cancer increases as the number of consumed cigarettes increases. Nevertheless, the estimated strength of this dose-response effect was negatively accelerated. After surpassing a threshold of 15 cigarettes per day, an increase in consumption led only to a small rise in perceived risk. However, the actual relationship between smoked cigarettes per day and lung cancer risk is at least proportional. Misjudging the cumulative risk of increasing exposure to risks could jeopardize appropriate behaviors, and in the worst case encourage extensive risk behaviors.

Unfortunately, not only the implications of repeated risk behavior can be misunderstood, but also the long-term effectiveness of precautions could be misconstrued. Birth control, for example, needs a continuing process of risk management. The risk of conception is relatively low on a single occasion of sexual intercourse, but accumulates over repeated occasions. Imagine a contraceptive method with a one-year reliability of 0.98 . Of 100 women who apply this method, 2 will become pregnant during one year of use. This outcome appears reassuring. However, with each additional year, the number of unwanted pregnancies will further increase. After a ten-year period, 20 percent of the same group of women will be pregnant, although they might still perceive their risk as 2 percent. Therefore, individuals need to understand how the risk of conception accumulates over repeated exposure, and to what degree this could be reduced through the use of contraceptive methods.

Shaklee and Fischhoff (1990) showed that most laypersons do not realize that contraceptive effectiveness declines over time. Thus, a short-term perspective on effectiveness may promote unrealistically optimistic estimations about long-term outcomes, since individuals are not aware how rapidly small risks add up. Since most effectiveness information about birth control methods is only presented for one year of use, individuals may have too much confidence in their precautions. Hence, from a health-educational perspective, contraceptive effectiveness information should be presented for short as well as long time periods to assist people in making informed choices. 
The importance of "complete" risk information becomes particularly relevant in the case of HIV prevention. Linville et al. (1993) asked male college students to rate the probability of an HIV transmission from male to female in one case and in 100 cases of protected sex. On average, the one-case probability of an HIV infection was overestimated, while the mean estimate for 100 cases was highly underestimated. Accordingly, public risk communication which does not emphasize how the risk of an HIV infection accumulates over repeated exposures, even for protected intercourse, could give recipients a dangerously wrong impression about their safety. To prevent a faulty understanding of cumulative risks and effectiveness, public health campaigns are needed that explicitly inform the public about how risk accumulates in the long run. Alternatively, as Shaklee and Fischhoff (1990) suggest, effectiveness estimates should be presented for all the time periods that are relevant to people's decisions.

Estimating a health risk becomes even more complex when multiple risks are considered. Certain risk behaviors, such as smoking and alcohol consumption, result in a combined risk that is greater than the sum of the single risks. However, empirical evidence shows that people have problems in understanding such synergistic relations. Hermand et al. (1997) demonstrated that study participants believed that engaging in only one risk behavior (heavy alcohol consumption or heavy smoking) results in the same risk as engaging in both at the same time. Hence, the two risks have been considered as disjunctive instead of synergistic. Hermand et al.'s (1997) research makes evident that communication about harmful effects of hazards should include information about potential synergistic or additional effects, as otherwise people might seriously misconstrue their overall risk.

In sum, providing information is a necessary first step in the process of changing health behaviors. However, the processing of health-related information could be a complex task for recipients, which may result in severe pitfalls. Individuals might harbor erroneous beliefs about health risks, which could be due to missing information, misinformation, or inadequate or biased processing. Therefore, educational efforts must be sensitive to the psychology of people's decision making. To facilitate the understanding of risks, different information must be supplied, such as (a) the relative risks of acquiring one disease versus another, (b) how risk increases over time and how precaution effectiveness declines over time, and (c) how different risk factors cumulate to provide the overall risk.

\section{Underestimating Self-relevant Risk}

At first glance, perceiving a health threat seems to be the most obvious prerequisite for the motivation to remove a risk behavior. Consequently, a central task for health communication is not only to provide information about the existence and magnitude of a certain risk, but also to increase the subjective relevance of a health issue to focus individuals' attention on information pertaining directly to their own risk. However, general perceptions of risk 
(e.g., "Smoking is dangerous") and personal perceptions of risk (e.g., “I am at risk because I am a smoker") often differ to a great extent. Individuals could be well informed about general aspects of certain risks and precautions (e.g., most smokers acknowledge that smoking can cause diseases), but, nevertheless, many might not feel personally at risk (Weinstein, 1998).

Especially when it comes to a comparison with similar others (for an overview of social comparison mechanisms, see Suls and Wheeler, 2000), one's view of the risk is somewhat distorted. On average, individuals tend to see themselves as being less likely than others to experience health problems in the future. For example, when asked how they judge their risk of becoming HIV-infected compared to an average peer of the same sex and age (the "average risk"), participants typically give a below-average estimate (e.g., Hahn and Renner, 1998). This bias in direct comparative risk perception, that has been coined "unrealistic optimism" or "optimistic bias" (Perloff and Fetzer, 1986; Weinstein, 1980; this volume), reflects the difference between the perceived risk for oneself and that for others, and belongs to the broader construct of defensive optimism (Schwarzer, 1994).

Similarly, Thompson et al. (1996) showed that individuals are prone to an "illusion of safety in a risky world." The authors asked undergraduates to list factors that make it less likely to become infected by HIV in comparison to an average student at their college. Despite being well informed about HIV, participants discounted their risk in terms of irrelevant factors. For example, 30 percent stated that they were less at risk than an average student because they were monogamous. These empirical findings are particularly disturbing because the majority of college students are only serially monogamous, which means that one monogamous relationship is followed by another. Hence, people may acknowledge a certain risk for others, but are reluctant to admit that they are at risk themselves.

This phenomenon becomes even more obvious in the study conducted by Hahn and Renner (1998). They asked smokers to characterize the typical smoking behavior that is necessary to be at a high risk for lung cancer in terms of the number of years of smoking, the daily amount of cigarettes consumed, and the cigarettes' nicotine content. These subjective estimates for the "risk prototype" were compared with participants' own smoking behavior. Results showed that smokers estimated their lung cancer risk only as being average when their own behavior was equivalent to that of the risk stereotype. Or, to put this effect more bluntly, even smokers who demonstrated a smoking behavior that they themselves judged as highly risky nonetheless viewed their own personal risk as only average.

Unrealistic optimism could be an important barrier for convincing people to change their health habits because optimistic bias may function to dissuade them from engaging in protective health actions. However, optimistic bias is a matter of degree. Individuals do not distort reality completely. This becomes most obvious when they are asked to estimate the absolute risk for themselves and for the average peer, as opposed to a direct comparison. Renner et al. (2000) showed that absolute risk perceptions reveal relative accuracy, since older participants perceived their risk for cardiovascular diseases as 
Perceived risk for cardiovascular diseases

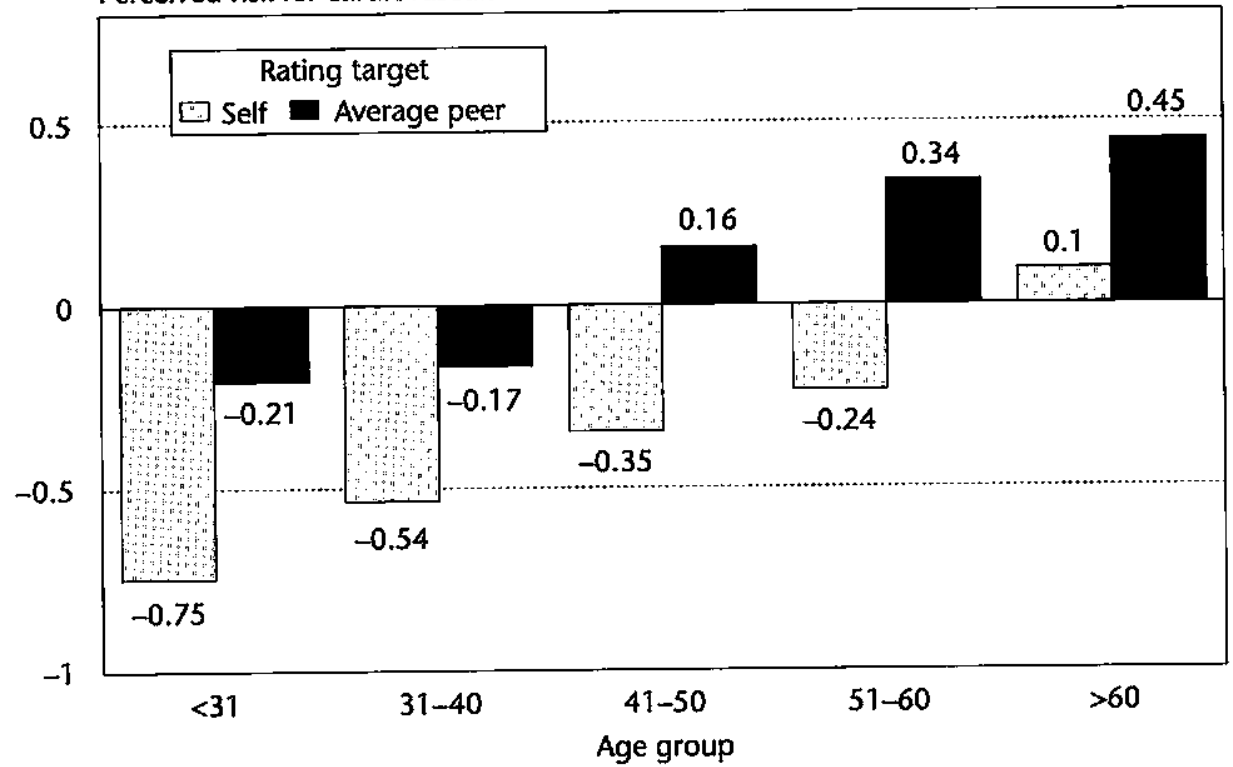

Figure 7.1 Mean absolute risk judgments for self and an average peer to cardiovascular diseases as a function of age.

being higher than younger ones did. Nevertheless, they still assumed that they were less vulnerable than their peers (see Figure 7.1).

The observed effect of aging on perceived risk leads to the conclusion that people acknowledge a higher risk with increasing age and declining health, but that aging did not curb unrealistic comparative risk perceptions. Further, these results suggest that defensive optimism is determined by the tendency to see others as more at risk from negative events than oneself. The fact that individuals harbor pessimistic biases for others may represent a mechanism by which they maintain a comparatively optimistic outlook for themselves, despite realizing that health-related risks do increase with age. This might satisfy a need for accuracy by acknowledging more objective risk at an absolute level, while also serving self-protective needs by maintaining a pessimistic view of others at the same time (Armor and Taylor, 1998; Taylor and Shepperd, 1998; Whitley and Hern, 1991).

This leads to the question about how health promotion campaigns should communicate information about risks in order to reduce unrealistic optimistic risk perceptions. The guiding principles proposed by health campaigns for risk reductions usually only list risk factors impersonally, or show high-risk persons. This may lead to an underestimation of personal risk because individuals may think that a number of risk factors do not apply to them by fostering a risk stereotype which is perceived as dissimilar (Hahn and Renner, 1998; Weinstein and Klein, 1995). Consequently, risk communication that provides only information about general risk may make people aware of a 
risk ("Smoking causes coronary heart disease"), but at the same time it may foster an underestimation of the magnitude of the risk for oneself ( ${ }^{4}$ It is unlikely that this will happen to me"). One possibility to reduce unrealistic optimism is to provide additional information about the risk faced by an average peer. Lachendro and Weinstein (1982), for instance, asked participants to come up with a number of possible risk-reducing factors that typical peers might list. This experimental intervention resulted in lower unrealistic optimism since the participants were encouraged to explicitly consider moderating factors in other persons that they usually only found in themselves. Weinstein (this volume) proposes that we are unrealistically optimistic because we do not think carefully about the target under comparison.

Such additional information may help people locate their risk status more accurately and become motivated to change risky behaviors. This type of message establishes more clearly who is likely to be affected, but it is still ambiguous since recipients have to infer the magnitude of their personal risk. In order to reduce this ambiguity, people should be informed about the existence of a health risk in a personalized manner to enhance self-relevance, and, furthermore, they should imagine themselves as possible victims, unless they take the necessary precautions to overcome a tendency to deny that the advice applies to them.

One frequently used method for communicating personalized health risk is to assess individuals' risk status by either self-administered questionnaires or biomedical measures. From these data, and from epidemiological statistics, estimates of individuals' morbidity or mortality risk are calculated and given as feedback (e.g., "Your actual age is 55 years, but your risk age is $6 \mathrm{I}$ years. If you quit smoking, you can add 5 years to your present life expectancy"). This method is called "health risk appraisal" (Strecher and Kreuter, 1995).

However, empirical studies have shown that individuals process and respond to feedback about their personal health risk in a self-defensive manner. Jemmott et al. (1986) invented an experimental procedure to study judgments about favorable and unfavorable medical information. An often-replicated finding is that participants who were made to believe that they suffer from (hypothetical) thiamine acetylase (TAA) deficiency perceived their test result as less accurate and rated TAA deficiency as a less serious threat to their health than their experimental counterparts, who were made to believe that they did not have a TAA deficiency. Similar results were found in experimental studies of appraisals of cholesterol and blood pressure test results (Croyle, 1990; Croyle et al., 1993), gum disease test results (McCaul et al., 1992), and a hypothetical bacterial condition (Cioffi, 1991). Croyle et al. (1997) interpreted these findings as evidence for motivated reasoning, arguing that people who are informed that they have an elevated risk of disease minimize the seriousness of the health threat posed by the risk factor and derogate the validity of the risk factor test in order to maintain a favorable sense of their health.

Does this mean that even individualized risk communication is ineffective in motivating people to change their behavior? People do not indiscriminately 
derogate or deny unfavorable risk information. Croyle and Sande (1988) reported that individuals who believed that they suffered from a TAA deficiency showed evidence for denial, but they also recalled more diagnosis-consistent symptoms and risk-increasing behaviors (e.g., use of aspirin or Tylenol, getting less than seven hours of sleep, skipping a meal) than individuals who considered themselves to be on the safe side. More interestingly, the higher the consistency with which an individual could recall symptoms, the less they denigrated the validity of the diagnostic test.

Accordingly, participants minimized the implications of the diagnosis, while simultaneously searching for diagnosis-confirming evidence. Ditto and Croyle (1995) explained these conflicting results by suggesting that minimizing the threat serves primarily to reduce negative affect. This need not necessarily conflict with instrumental coping behavior. Ditto et al. (1988) further observed that unfavorable medical feedback causes prominent denial only when recipients believed that they had no possibility of reducing the threat by modifying their behavior.

This makes obvious that the adoption of health behaviors could not be viewed simplistically as a response to a health threat. Risk information alone does not help people to change risky behaviors because it does not provide meaningful information about how to manage behavioral changes. Initial risk perception seems to be advantageous to help people become motivated to change, but later on other factors are more influential in the self-regulation process. This state of affairs has encouraged health psychologists to design more complex models that include an integrated pattern of determinants and processes of change.

\section{Forming an Intention to Change: Continuum Models of Health Behavior}

Most health behavior theories concentrate on the process leading to the formation of an explicit intention (e.g., "I intend to quit smoking this weekend") because they propose that a person's behavior is the outcome of conscious intentions. The intention strength is assumed to be the key indicator of cognitive preparedness for action (Abraham and Sheeran, 2000). In line with this assumption, Godin and Kok (1996), who examined 19 studies, found a mean correlation of 0.46 between intention and health behavior, such as exercise, screening attendance, and addictions. In general, Abraham and Sheeran (2000) expect behavioral intention measures to account for $20-25$ percent of the variance $^{1}$ in health behavior measures.

The process of intention formation is in turn assumed to be determined by certain beliefs and attitudes. Therefore, in the past, the focus of such models has been on identifying a parsimonious set of predictors that included constructs such as perceived barriers, social norms, disease severity, personal vulnerability, perceived self-efficacy, etc. These are then combined into a single prediction equation for explaining behavioral intention and individual 
health behavior change (Weinstein et al., 1998b). Since this implies that the way in which these predictors combine to influence actions is expected to be the same for everyone, these models are called continuum models.

The most prominent approaches are the Theory of Reasoned Action, the Theory of Planned Behavior, and the Protection Motivation Theory (for an overview and critique of these and other models, see Abraham and Sheeran, 2000; Armitage and Conner, 2000; Conner and Norman, 1996; Schwarzer, 1992; Wallston and Armstrong, 2002; Weinstein, 1993). The current revised versions of these continuum health behavior models share several common predictors. Two other variables beside risk perception are considered to play a major role in this process: (a) outcome expectancies, and (b) perceived self-efficacy (Bandura, 1997; 2000; Schwarzer, 1992; Weinstein, 1993). The wording of these determinants differs in different theories, but their meaning is about the same. For example, behavioral beliefs (as precursors of attitudes) can be equated to outcome expectancies, and behavioral control can be more or less matched to perceived self-efficacy (see also Wallston, 2001).

\section{Outcome Expectancies}

According to these theories, people not only need to be aware of a health threat, they also need enough knowledge about how to regulate their behavior. They need to understand the links between their actions and subsequent outcomes. These outcome expectancies can be the most influential beliefs in the motivation to change. A smoker may find more good reasons to quit than good reasons to continue smoking ("If I quit smoking then my friend will like me much more"), and while this imbalance may not lead directly to action, it can help to generate the intention to quit. Many of those cognitions represent social outcome expectancies by pertaining to the social consequences of a particular behavior. The pros and cons that are typical in rational decision making represent positive and negative outcome expectancies. However, such contingencies between actions and outcomes need not be explicitly worded and evaluated, they can also be rather diffuse mental representations, loaded with emotions. Outcome expectancies can also be understood as methods, or means-ends relationships, indicating that people know proper strategies to produce the desired effects.

\section{Perceived Self-efficacy}

The efficacy of a method has to be distinguished from the belief in one's personal efficacy to apply the method. Perceived self-efficacy portrays individuals' beliefs in their capabilities to exercise control over challenging demands and over their own functioning (Bandura, 1997; 2000). According to Bandura $(1997 ; 2000)$ perceived self-efficacy involves the regulation of thought 
processes, affective states, motivation, behavior, or changing environmental conditions. These beliefs are critical in approaching novel or difficult situations, or in adopting a strenuous self-regimen. People make an internal attribution in terms of personal competence when forecasting their behavior (e.g., "I am certain that I can quit smoking even if my friend continues to smoke."). Such optimistic self-beliefs influence the goals people set for themselves, what courses of action they choose to pursue, how much effort they invest in given endeavors, and how long they persevere in the face of barriers and setbacks. Some people harbor self-doubts and cannot motivate themselves. They see little point in even setting a goal if they believe they do not have what it takes to succeed. Thus, the intention to change a habit that affects health is to some degree dependent on a firm belief in one's capability to exercise control over that habit.

Perceived self-efficacy operates in concert with risk perception, outcome expectancies, and other factors when it comes to motivation to change. There is a large body of evidence documenting the influence of these three predictors on forming an intention. Unfortunately, self-efficacy research that employs behavioral intentions as the criterion variable is more frequent than research that addresses actual behaviors (for reviews see Bandura, 1997; Schwarzer and Fuchs, 1995; 1996). This may be partly due to methodological difficulties in health behavior assessment (Renner, 2001). Additionally, although continuum models assume an underlying process towards behavior change, most empirical studies are limited to cross-sectional designs where criterion variables (intentions and self-reported behaviors) are assessed at the same time as predictor variables (risk perception, outcome expectancies, and self-efficacy). Therefore, only little is known about the causal sequence and interplay of these factors. It is assumed that initial risk perception sets the stage, whereas outcome expectancies and perceived self-efficacy may emerge later. At the point in time when the behavioral intention is measured, the latter two emanate as the major predictors, whereas the former is often insubstantial (Schwarzer and Renner, 2000).

Apart from limitations at the empirical level, researchers have suggested two major theoretical deficiencies. First, a single prediction rule for describing behavior change implies that cognitive and behavioral change occur in a linear fashion, and that a "one-size-fits-all" intervention approach (Winders et al., 1999) is suitable for all individuals engaging in unhealthy behaviors. Consequently, it excludes qualitative changes during the course of time, such as stage transitions or recycling through phases. Weinstein et al. (1998a) noted that, according to continuum models, it is not important whether an intervention approach is targeted towards changing perceived vulnerability, perceived consequences, or perceived self-efficacy first. Hence, interventions are not required to be progressed in a certain sequence. Rather, they could be applied in any order, or even simultaneously.

Second, none of these models account for the post-intentional phase where goals are translated into action. The segment between intentions and behaviors is a black box. Theorizing about health behavior change, then, is reduced to the motivation phase only, while omitting the decisive action phase. 


\section{Different Processes at Different Stages: Dynamic Models of Health Behavior Change}

\section{The Transtheoretical Model of Behavior Change}

To overcome these limitations, stage theorists have made an attempt to consider process characteristics by proposing a number of qualitative stages. The Transtheoretical Model of Behavior Change (TTM) (e.g., DiClemente and Prochaska, 1982; Prochaska et al., 1992; 1998), for example, has become the most popular stage model. Its main feature is the implication that different types of cognitions may be important at different stages of the health behavior change process. The most common version of the TTM includes five discrete stages of health behavior change that are defined in terms of one's past behavior and future plans (pre-contemplation, contemplation, preparation, action, maintenance). For example, at the pre-contemplation stage, a problem drinker has no intention of stopping in the future. At the contemplation stage, he or she reflects about quitting sometime within the next six months, but does not make any specific plans for behavior change. At the preparation stage, the problem drinker resolves to quit within the next six months. The action stage includes individuals who have taken successful action for any period of time. If this abstinence has lasted for more than six months, the person is categorized as being in the maintenance stage. The five stages are expected to be mutually exclusive and qualitatively different. People could make multiple attempts to progress from pre-action stages to action. However, relapses could occur anytime, resulting in a spiral-like progression through the behavior-change process.

In addition to the described basic stages of change, the TTM also includes ten processes of change, the perceived pros and cons of changing, perceived self-efficacy and temptation. These additional constructs are conceptualized as causes for the transitions between the stages, whereby it is assumed that different factors influence different stage transitions.

The TTM has received a lot of attention, since its "practicability" for educational interventions is very appealing. However, the TTM has also been seriously criticized by several researchers. Bandura (2000) argued that different qualitative stages necessarily imply that individuals cannot move back in the transitions of stages (irreversibility), and they cannot progress from one stage to another while passing over another one (invariance). This requirement might be too conservative, but there are other significant disadvantages. Weinstein et al. (1998b) and Sutton $(2000 ; 2001)$ argued that the notion of stages might be flawed or circular, in that the stages are not genuinely qualitative, but are rather arbitrary distinctions within a continuous process. In particular, the proposed time frame for distinguishing between different qualitative stages is not conclusive. Furthermore, different studies have referred to different time frames for operational stage definitions. For instance, Velicer et al. (1985) defined contemplation as the time in which individuals seriously think about changing behavior within the next year, whereas Prochaska et al. (1994) defined contemplation as thinking about changing within the next 
six months. Why should individuals who intend to quit within the next six months (contemplators) be in a different qualitative stage of action-readiness than individuals who intend to quit within the next five months (preparers)? In line with this reasoning, Kraft et al. (1999) demonstrated within a sample of 4.21 Norwegian daily smokers, that pre-contemplators, contemplators, and preparers were not at different qualitative stages rather than at different places along an underlying continuum. Similarly, Courneya et al. (2000) reported that continuous measures of intention explained more variance in exercise behavior than the stage algorithm proposed by the TTM. Other researchers have examined the TTM and found that processes of change did not predict smoking stage movements (Herzog et al., 1999), and that stage-matched and stage-mismatched interventions with young adult smokers did not yield the hypothesized results (Quinlan and McCaul, 2000). Stages of change did not predict success in weight control in adult women, either (Jeffery et al., 1999). In sum, the TTM has received only weak support to date, which led Abraham et al. (2000) to conclude that TTM stage classifications are questionable.

Hence, these "stages" might be better understood as "process heuristics" to underscore the nature of the entire model. That is, the TTM can serve as a useful heuristic that describes a health behavior change process, which has not been the major focus of health behavior theories so far. In contrast to continuum models, stage models such as the transtheoretical model assume that factors producing movement toward action differ in respect to a person's stage. The identification of stages could bear important implications for intervention and treatment because it can be used to match stage position or readiness of change of the target group with particular intervention strategies (Oldenburg et al., 1999).

\section{The Precaution Adoption Process Mode}

In redirecting attention to a self-regulatory process, the transtheoretical model has served an important purpose for applied settings. However, the number of stages and how these stages should be defined is a major challenge for further research. The more recent Precaution Adoption Process Model (PAPM; Weinstein, 1988; this volume; Weinstein and Sandman, 1992) does not involve past behavior or any particular time frame in classification, and identifies people at seven stages: (1) unaware of the health action, (2) aware but not personally engaged, (3) engaged and trying to decide what to do, (4) decided not to act, (5) decided to act but not yet having acted, (6) acting, and (7) maintaining the new adopted health behavior. Hence, the PAPM extends the TTM by further differentiating the first two stages of the transtheoretical model: it distinguishes between people who are unaware of an issue (Stage 1 ), and people who are aware but not personally engaged (Stage 2). Second, it discriminates people who are engaged and considering their action (Stage 3) from those who decided not to act (Stage 4). Similarly to the TTM, the PAPM proposes certain factors that influence different stage transitions. Perceived vulnerability is assumed to be the necessary essence to move individuals 
from being aware to deciding to take action. Situational barriers determine whether individuals progress from the intention to act to actually implementing the behavior.

This model has been applied to home testing for radon (Weinstein et al., 1998a; for further details see also Chapter 2, this volume). The focus of this experimental study was on two different transitions: from being undecided about testing one's home (Stage 3), to deciding to test (Stage 5), and from this stage to actually ordering the test (Stage 6).

As expected, the results show that stage-matched interventions were more effective than stage-mismatched ones. However, the combination of both treatments was at least as effective as the stage-matched single treatments for undecided participants or decided-to-act participants. The combined treatment, for instance, prompted 54 percent of the participants to form an intention to test amongst the undecided group, whereas the matched vulnerability treatment encouraged only 42 percent to develop a decision to act. This result suggests that administrating matched treatments is not necessarily the most productive approach to encourage health behavior change - combination treatments might be even more successful. In terms of utility, Abraham et al. (2000) argued that as long as targeting stage-defined audiences is problematic and causes additional costs, investment in stage-specific interventions is not justified. Combining interventions that are designed to promote a variety of cognitive changes might be less expensive, since this does not require prior screening for action preparedness within the audience, and above all they might be even more successful. Nonetheless, it would be premature to conclude that stage-tailored interventions are not useful since they can only be as good as the underlying stage definitions. Refining stage definitions or different stage conceptions might generate stronger support for the stage framework.

\section{The Health Action Process Approach}

Another more parsimonious model is the Health Action Process Approach (HAPA; Schwarzer, 1992; 1999; Schwarzer and Fuchs, 1995; 1996). This health behavior change model is regarded as a heuristic to better understand the complex mechanisms that operate when people become motivated to change, and when they attempt to resist temptations. It applies to all health-compromising and health-enhancing behaviors and pays particular attention to post-intentional mechanisms, and it conveys an explicit self-regulation perspective. It suggests a distinction between (a) pre-intentional motivation processes that lead to a behavioral intention, and (b) post-intentional volition processes that lead to actual health behavior. Within both phases, different patterns of socialcognitive predictors may emerge (see Figure 7.2).

\section{Pre-intentional Motivation Processes}

In the initial motivation phase, a person develops an intention to act. In this phase, risk perception ("I have a high risk of suffering a heart attack because of my high cholesterol level and body weight") is merely seen as a distal 


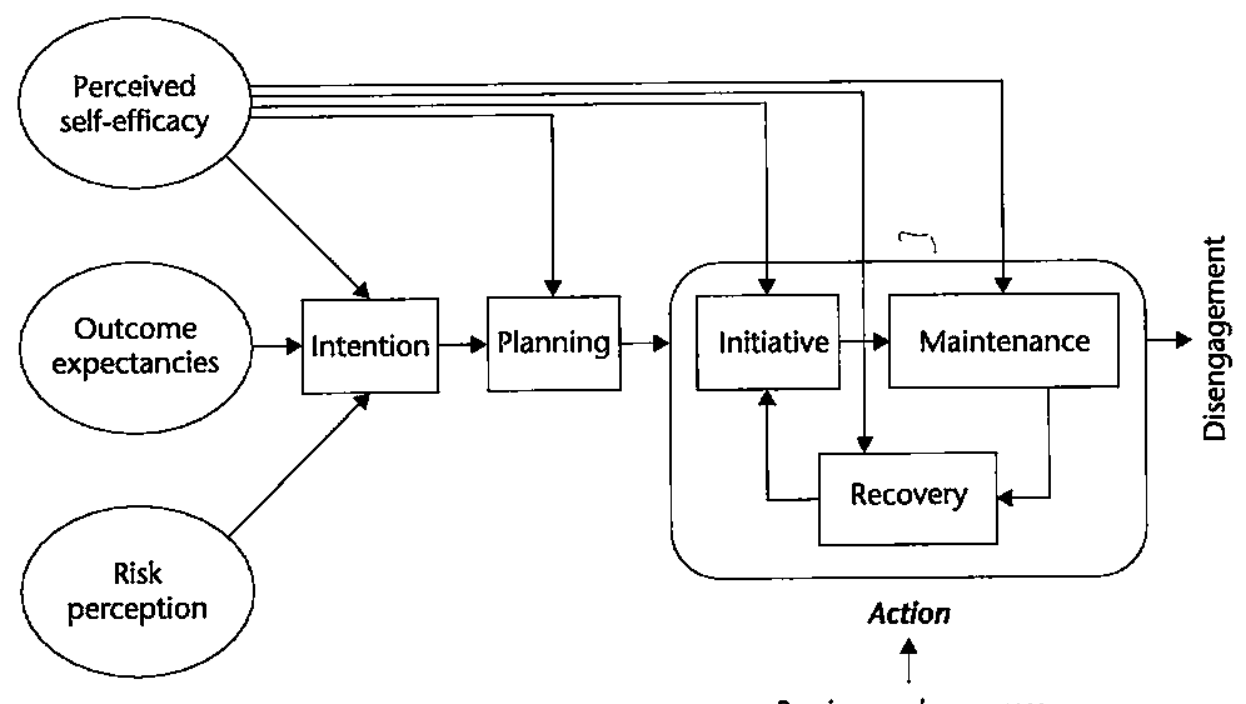

Barriers and resources

Figure 7.2 The Health Action Process Approach.

antecedent within the motivation phase. It may include not only the perceived severity of possible health threats, but also one's personal vulnerability to fall prey to them. Risk perception in itself is insufficient to enable a person to form an intention. Rather, it sets the stage for a contemplation process and further elaboration of thoughts about consequences and competencies. Similarly, outcome expectancies ("If I eat healthful foods, I will reduce my cardiovascular risk") are chiefly seen as being important in the motivation phase, when a person balances the pros and cons of certain behavior consequences. Further, one needs to believe in one's capability to perform a desired action ("I am capable of controlling my healthy diet in spite of sweet temptations"), otherwise one will fail to initiate action. Outcome expectancies operate in concert with perceived self-efficacy, both of which contribute substantially to the forming of an intention (Schwarzer and Renner, 2000). Both resources are needed, especially for implementing difficult or complex behaviors, such as body weight control (Bagozzi and Edwards, 1999).

\section{Post-intentional Volition Processes}

After a person develops an inclination towards a particular health behavior, the "good intention" has to be transformed into detailed instructions on how to perform the desired action. The importance of planning has been emphasized by Gollwitzer (1999), who reviews research on what he calls "implementation intentions" (see also Gollwitzer and Oettingen, 2000). These plans specify the when, where, and how of a desired action and carry the structure of "When situation S arises, I will perform response R." Consequently, situational circumstances or opportunities are cognitively linked to one's goal behavior. It is argued that goals do not induce actions directly; rather, they need to 
be mediated by highly specific plans (Taylor et al., 1998). For example, the pursuit of health promotion goals such as strenuous physical exercise, and disease-prevention goals such as cancer screening are facilitated by mental process simulation. Sheeran and Orbell (2000) asked women who were due for a cervical smear test to write down when, where, and how they will make an appointment. These women were more likely to actually attend for screening compared with controls who were equally motivated to attend, but who did not specify their implementation intention. Thus, a global intention can be specified by a set of subordinate intentions and action plans that contain proximal goals and algorithms of action sequences.

The volition process may be influenced by outcome expectancies, but it is more strongly affected by self-efficacy because the number and quality of action plans depend on one's perceived competence and experience. Selfefficacy beliefs influence the cognitive construction of specific action plans, for example by visualizing scenarios that may guide goal attainment (Bandura, 1997). These post-decisional, pre-actional cognitions are necessary for successful action because otherwise the person would act impulsively in a trialand-error fashion, not knowing where to allocate the available resources.

If the appropriate opportunity for a desired action is clearly defined in terms of when, where, and how, the probability for procrastination is reduced. People take initiative when the critical situation arises and give it a try. This requires a firm self-belief in being capable of performing the action. People who do not hold such beliefs see little point in even trying.

Once an action has been initiated, it has to be controlled by cognitions in order to be maintained (unless it is purely habitual, e.g., brushing teeth). This is not achieved through a single act of will, but involves the development of self-regulatory skills and strategies. It embraces various means to influence one's own motivation and behaviors, such as the setting of attainable, proximal subgoals, creating incentives, drawing from an array of coping options, and mobilizing social support. The action has to be protected from being interrupted and abandoned prematurely due to incompatible competing intentions that may dominate an ongoing behavior. Meta-cognitive activity (e.g., monitoring one's self-regulatory strategies) is needed in order to complete the primary action and to suppress distracting secondary action tendencies. Daily physical exercise, for example, requires self-regulatory processes in order to secure effort, and persistence to keep adverse motivational tendencies at bay (such as the desire to eat, socialize, or sleep) until these tendencies are allowed to prevail for the required time period (see also Carver and Scheier, I996; 1998). Perceived self-efficacy determines the amount of effort invested and the perseverance. People who harbor self-doubts are more inclined to anticipate failure scenarios, worry about possible performance deficiencies, and abort their attempts prematurely. Those with an optimistic sense of self-efficacy, on the other hand, visualize success scenarios that guide the action and let them persevere even in the face of obstacles. They recover quickly when running into unforeseen difficulties.

Adherence to a self-imposed health behavior is difficult because of fluctuations in performance such as improvements, plateaus, setbacks, and failures. 
Hence, competent relapse management is needed to recover from setbacks. Some people rapidly abandon their newly adopted behavior when they fail to get quick results. When they enter high-risk situations (e.g., a bar where others smoke), they cannot resist due to a lack of self-efficacy. At this point, a belief in one's capability to recover is needed. In studying addictive behaviors, Marlatt et al. (1995) have suggested distinguishing between recovery selfefficacy, action self-efficacy, and coping self-efficacy. The authors argue that the competence to recover is different from the competence enlisted to commence an action. Restoration, harm reduction, and renewal of motivation are serviceable strategies within the context of health self-regulation.

Disengagement from the goal before achieving it can be evidence for lack of persistence and, thus, an indication of self-regulatory failure. In the case of repeated failures, disengagement or scaling back the goal becomes an option, which may be adaptive. For example, if the goal was set too high or if the situation has changed and becomes more difficult than before, it is seldom worthwhile to continue the struggle. In the case of health-compromising behaviors, giving up is not a tenable option. Better self-regulatory skills have to be developed and unique approaches to the problem need to be taken. The experience of failure can be a useful learning experience to build up more competence, under the condition that the individual makes a beneficial causal attribution of the episode and practices constructive self-talk to renew the motivation.

\section{Phase-specific Self-efficacy: When Beliefs Make a Difference}

Optimistic self-beliefs may be phase-specific within a self-regulatory cycle. For example, some people may have high confidence in their ability to set ambitious goals and to take initiative, but little confidence in their ability to maintain the desired behaviors. In contrast, others may have high confidence in their ability to resist temptation and to recover from setbacks, but little confidence in getting started. Thus, perceived self-efficacy is seen as functional at different levels and at different points in time within a self-regulatory goal attainment process. It might be useful to subdivide the construct in a phase-specific manner in order to characterize these functions (Dijkstra and de Vries, 2000; Marlatt et al., 1995). Action self-efficacy makes a difference in the pre-intentional phase. Individuals high in self-efficacy imagine success scenarios, anticipate potential outcomes of diverse strategies, and take the initiative in trying to adopt a new behavior (Bagozzi and Edwards, 2000). People with less self-efficacy, on the other hand, imagine failure scenarios, harbor self-doubts, and procrastinate. Those with high action self-efficacy choose to perform more challenging tasks (Bandura, 1997). They set higher goals for themselves and take the initiative more easily. Coping self-efficacy, on the other hand, describes optimistic beliefs about one's capability to deal with barriers that arise during the postintentional phase. A new health behavior might turn out to be much more difficult to adhere to than expected, but a self-efficacious person responds confidently with better strategies, more effort, and prolonged persistence to overcome such hurdles. Once an action has been taken, high coping self-efficacious persons invest more effort and persist 
longer than those who are low in self-efficacy. When setbacks occur, they recover more quickly and maintain the commitment to their goals.

In order to examine the effects of social-cognitive factors on nutrition behaviors and corresponding behavioral intentions, a study was launched with 524 men and women with an average age of 43 years (Schwarzer and Renner, 2000). The study does not allow an experimental test of the HAPA model, but it does include some crucial variables, and, therefore, it permits the exploration of some of the proposed relationships and helps to establish empirically the conceptual distinction between action self-efficacy and coping self-efficacy. The study covers the three predictors within the pre-intentional phase (risk perception, outcome expectancies, and action self-efficacy) and the intention phase to adopt a healthy diet at Wave 1 . The study also includes coping self-efficacy in the post-intentional phase half a year later, covering two preventive nutrition behaviors. It is assumed that behavioral intention and coping self-efficacy served as mediators linking the three predictors with two self-reported nutrition behaviors, namely low-fat and high-fiber dietary intake, six months later, at Wave 2. The questions are, in particular, how strong the associations will be and what kind of prediction pattern will emerge.

A set of 22 questionnaire items related to nutrition was designed to assess seven constructs, four at Time 1 and three at Time 2. Risk perception, outcome expectancies, action self-efficacy, and intentions were measured first, whereas coping self-efficacy, low-fat diet, and high-fiber diet were measured half a year later.

For the assessment of comparative risk perception, respondents were asked to estimate their risk for heart disease, high blood pressure, and a stroke. Responses were given on seven-point scales anchored at much below average (-3) and much above average (+3).

Outcome expectancies were measured by three items. Participants were asked, "What do you think will be the personal consequences for yourself if you adopt a low-fat, high-fiber diet?" After this header, responses were elicited to three specific questions: "If I stick to a low-fat, high-fiber diet, then ... (a) I would feel physically more attractive, (b) mentally I would feel better, and (c) I would have no (or fewer) body weight problems."

The general stem for all perceived self-efficacy items was "How certain are you that you could overcome the following barriers?" Action self-efficacy consisted of two indicators: "I can manage to stick to healthful food, (a) ... even if I have to make a detailed plan, (b) ... . even if I have to rethink my entire way of nutrition." Coping self-efficacy consisted of three indicators: "I can manage to stick to healthful food, (a) ... . even if I have to try several times until it works, (b) ... . even if I need a long time to develop the necessary routines, (c) ... even if I do not receive a great deal of support from others when making my first attempts."

The intention to adopt preventive nutrition habits was assessed with four items: "I intend to eat only a very small amount of fat (such as saturated fat, cheese, butter) over the next months," "I intend to live a healthier life," "I intend to eat healthful foods over the next months," and "I intend to invest more into my health." 


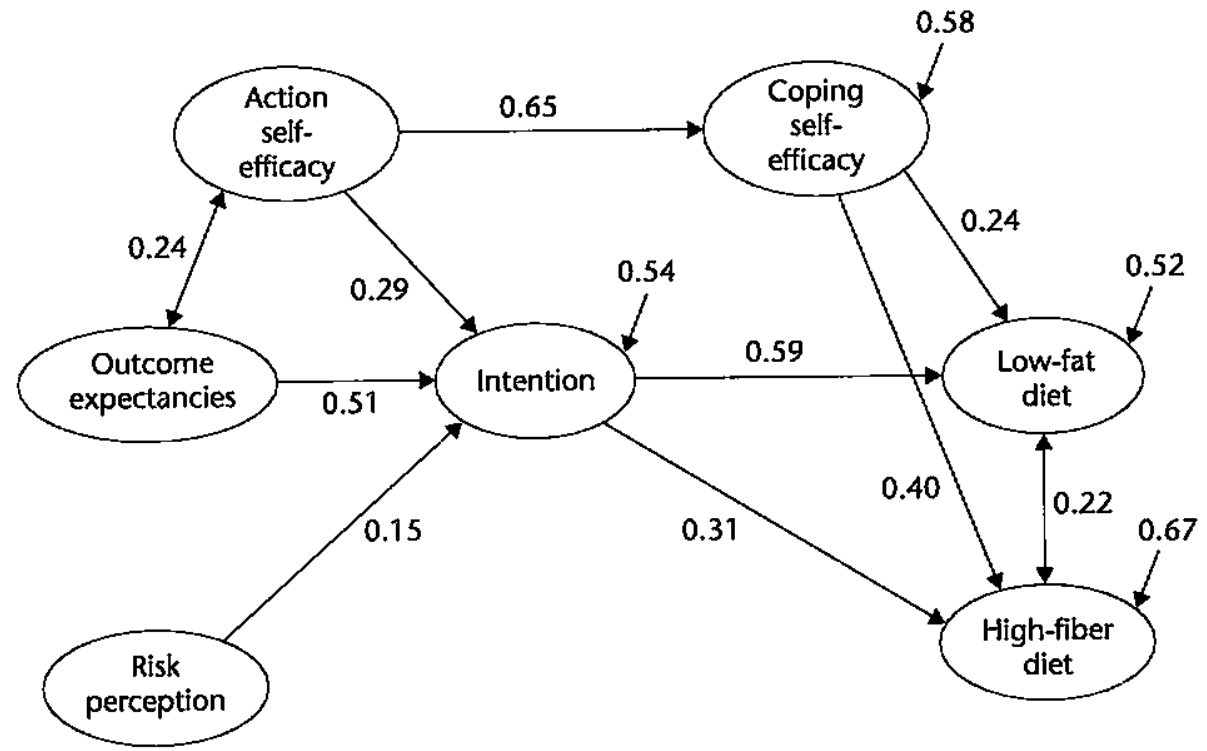

Figure 7.3 Causal model predicting preventive nutrition by phase-specific self-efficacy.

There were two dimensions of nutrition behavior half a year later. One related to a high-fiber diet with three items: "I eat a lot of fresh fruit and vegetables," "I observe a high vitamin diet," and "I stick to a balanced diet." The other dimension, related to a low-fat diet, contained four items: "I follow a low-fat diet," "When I eat milk products or drink milk, I choose low-fat products (such as low-fat milk or yogurt)," "I avoid foods with cholesterol," and "I am aware of my calorie intake."

To examine the associations between the variables, a structural equations approach was chosen. The model fit was good with $G F I=0.98, R M R=0.051$, $R M S E A=0.038(p=0.73)$, and $\chi^{2}=348.93(d f=197 ; p<0.001)$ (Figure 7.3).

In the prediction of the intention, the hypothesized rank order was confirmed: (a) outcome expectancies (0.50), (b) self-efficacy (0.28), and (c) risk perception (0.15). The relationship between action self-efficacy (Time 1) and coping self-efficacy (Time 2) was 0.62 . The latter, in conjunction with the intention, predicted the two behavior dimensions very well. Of the low-fat diet variation, 48 percent was accounted for, whereas of the high-fiber diet variation, 33 percent was accounted for by intention and coping self-efficacy. Low-fat diet was better predicted by the intention, whereas high-fiber diet was better predicted by coping self-efficacy.

All current popular health behavior theories suggest that an intention to change is probably the best predictor of subsequent behavior, unless unexpected barriers make the adoption of a health behavior unlikely. The present study has confirmed this assumption. The two nutrition behaviors were 
well predicted by the behavioral intention that the research participants had expressed half a year before.

A second assumption, based on the HAPA model, was the differential prediction within both the motivation phase and the volition phase. In the preintentional phase a weaker influence of perceived action self-efficacy on intentions was expected, compared to the influence of outcome expectancies. In the post-intentional phase, however, a stronger influence of perceived coping self-efficacy on behavior compared to that of outcome expectancies was assumed. Self-efficacious individuals are expected to develop more optimistic success scenarios for behavioral change, enhanced initiative, superior resistance in the face of temptation, and improved recovery after setbacks. Outcome expectancies, on the other hand, lose their importance at later stages of behavioral change, as confirmed by the present data.

\section{Conclusions}

\section{Risk Communication or Resource Communication?}

This chapter has described some social-cognitive factors that inhibit or promote individual health behavior change. Knowledge is certainly a precondition for health behavior change. In general, there is a great public interest in health-related information. Internet users, for example, who were asked about the future activities they intend to focus on, mentioned "health and medicine" as one of the top five areas (Brown, 1996). However, regardless of the vast amount of available information and attention it receives, appropriate health behavior change can only emerge if the information presented is processed accurately. Particular risk information can be multifaceted and complex, causing diverse misapprehension in the audience. To support comprehension, the public should be informed of the relative risk of acquiring one disease versus another, the relative impact of various risk factors over time, and the benefits derived from changing a targeted behavior.

To enhance perceived self-relevance of risk information, and in order to decrease defensive optimism, recipients should be informed about their risk relative to similar others, or, even better, should receive personalized risk information. Risk communicators could achieve quite different effects if they choose to describe the risk of one exposure in comparison to cumulative exposure. They could cast more or less favorable light on health-related behaviors, depending on the chosen length of the communicated time horizon. Considering the lifetime-cumulative risk of experiencing a stroke raises the perceived probability of disease and susceptibility, as opposed to only considering the risk over a five-year period. In view of that, the detrimental effects of risk factors could be emphasized by communicating the magnitude of harm in the long run. In contrast, the effectiveness of protective measures could be better communicated by using a shorter time frame. Becoming aware of one's own risk is indeed a necessary prerequisite, but by no means a sufficient one to 
motivate health behavior change. Following initial risk communication, it is mandatory to make people aware of their coping resources, such as their capability to change a refractory behavior. Resource communication is recommended at advanced stages of change. It shifts the focus towards the actual means and opportunities of behavior change as well as the optimistic beliefs of being competent to handle challenging risk situations. When people have reached a post-intentional stage, they need not be scared but rather encouraged to master their health goals.

\section{Considering Stages of Health Behavioral Change}

Interventions need to be theory-based and require scientific evaluation. Otherwise, the outcomes cannot be explained and accurately assessed in terms of those factors that may allow generalizations and could be adopted by others. Much progress has been achieved in the last decade. The ongoing debate on continuum models and stage models of health behavior change has sparked a great deal of good research and theoretical elaboration (for an overview see Armitage and Conner, 2000; Sutton, 2000; Wallston and Armstrong, 2002). The two major continuum models, the Protection Motivation Theory (PMT) and the Theory of Reasoned Action (TRA) or its variant Theory of Planned Behavior (TPB), are "intention models." They are designed to "predict" intentions, and they do this well. However, practically, this is mostly done in cross-sectional correlation studies. The models do not consider postintentional processes, which can be seen as the main shortcoming (see Schwarzer, 1992). Stage models, in contrast, emphasize pre-intentional as well as post-intentional processes.

Stage models assume that behavior change involves movement through a sequence of discrete, qualitatively distinct, stages. Different patterns of predictors are believed to be relevant at different stages. Hence, people at one stage may require different interventions than people at another stage. The transtheoretical model (TTM; Prochaska et al., 1992; 1994; 1998) is the earliest and most popular of the stage models. It includes 15 constructs drawn from different theories. Thus, it is not parsimonious, and it suffers from a number of further problems, such as lack of standardized instruments, particularly for the five stages of change, logical flaws in the staging algorithms, poor specification of the causal relationships among the constructs, frequent misinterpretation of cross-sectional data on stages of change, and confusion about the nature of stage models and how they should be tested (Sutton, 2000; 2001).

The precaution adoption process model (PAPM; Weinstein, 1988; 1993; 2000; this volume) is a well-founded stage model that defeats the shortcomings of the TTM. So far, two of its stages have been experimentally confirmed (Weinstein et al., 1998a).

The health action process approach (HAPA; Schwarzer, 1992; 1999) is a hybrid model. It is conceptualized as two stages: the first one is a continuum phase, 
incorporating, more or less, the PMT and TPB constructs, and the second one a logical sequence of post-intentional processes. The idea was to adopt the strongest parts from earlier theories and arrive at a fruitful integration, conceptually based on Bandura's (1997) social-cognitive theory.

There is a large extent of similarity and overlap among constructs and among models, but there are also distinct features with clear strengths and weaknesses. It is of note that some parts of old theories can be converted into better founded and more recent constructs. Resolution of controversies requires clearer definitions of constructs and a more thorough examination of the validity of those constructs.

Stage models bear the potential of creating a rationale for stage-matched treatments that encourage or help individuals to get on track or master a difficult course of action. Interventions should be tailored to fit the needs of the recipients. According to the HAPA model, at least two different phases should be distinguished: a motivational or pre-intentional phase that results in intention formation, and a volitional or post-decisional phase that refers to the actual adoption and maintenance of a health behavior. For people who are in the pre-intentional phase, enhancing perceived vulnerability would be the first step, followed by improving outcome expectancies and action self-efficacy. For their counterparts in the post-intentional phase, it would be more suitable to enhance goal prioritization, implementation intentions, and action plans. Persons who are ready to act should be encouraged to form plans which specify when, where and how a desired action is to be undertaken. Forming plans depends to a large extent on action self-efficacy, since the latter establishes how challenging the chosen action will be, how much effort someone needs to invest, and how much persistence is necessary. People will not even try to enact behaviors they do not feel capable of performing. Resource communication, therefore, should lead to greater confidence in one's capability to control health-related behavior. This also applies to relapse management, after people have failed to maintain their desired health behaviors. Recovery self-efficacy is a valuable resource that needs to be developed and cultivated, particularly in those who strive to overcome their personal shortcomings, such as being dependent on addictive substances.

\section{Acknowledgments}

We would like to thank Kenneth Wallston and Jerry Suls for their helpful comments. We would also like to thank Tony Arthur, Judith Bäßler and Mary Wegner for their advice and support throughout the stages of drafting and editing.

The research was partly supported by the Deutsche Forschungsgemeinschaft (Grant Schw 208/1 I-01-03).

Correspondence concerning this chapter should be sent to: Brita Renner, Department of Psychologie, Ernst-Moritz-Arndt-Universität Greifswald, FranzMehringstr.47, 17487 Greifswald, Germany; e-mail: renner@uni-greifswald.de 


\section{Note}

1. Abraham and Sheeran (2000) based their calculation on different empirical studies. The explained variance in health behavior measures is calculated by squaring the correlation between behavioral intention and behavior and multiplying the sum by 100 . For example, a correlation of 0.46 accounts for 21 percent of the variation.

\section{References}

Abraham, C., Norman, P., and Conner, M. (2000). Towards a psychology of healthrelated behavior change. In P. Norman, C. Abraham, and M. Conner (Eds.), Understanding and Changing Health Behavior (pp. 343-69). Amsterdam: Harwood Academic Publishers.

Abraham, C., and Sheeran, P. (2000). Understanding and changing health behavior: From health beliefs to self-regulation. In P. Norman, C. Abraham, and M. Conner (Eds.), Understanding and Changing Health Behavior (pp. 3-24). Amsterdam: Harwood Academic Publishers.

Armitage, C. J., and Conner, M. (2000). Social cognition models and health behaviour. Psychology and Health, 15, 173-89.

Armor, D. A., and Taylor, S. E. (1998). Situated optimism: Specific outcome expectancies and self-regulation. In M. P. Zanna (Ed.), Advances in Experimental Social Psychology (Vol. 30, pp. 309-79). New York: Academic Press.

Bagozzi, R. P., and Edwards, E. A. (1999). Goal-striving and the implementation of goal intentions in the regulation of body weight. Psychology and Health, 13, 593-621. Bagozzi, R. P., and Edwards, E. A. (2000). Goal setting and goal pursuit in the regulation of body weight. In P. Norman, C. Abraham, and M. Conner (Eds.), Understanding and Changing Health Behavior (pp. 261-97). Amsterdam: Harwood Academic Publishers. Bandura, A. (1997). Self-efficacy: The Exercise of Control. New York: Freeman.

Bandura, A. (2000). Health promotion from the perspective of social cognitive theory. In P. Norman, C. Abraham, and M. Conner (Eds.), Understanding and Changing Health Behavior (pp. 299-339). Amsterdam: Harwood Academic Publishers.

Bochow, M. (2000). Wie leben schwule Männer heute? [How do gay men live today?] Bundesgesundheitsblatt, Gesundheitsforschung, Gesundheitsschutz, 43, 677-82.

Brown, M. S. (1996). Polish and glitz aside, net resources fall short on the content yardstick. Medicine on the Net, 2, 7-8.

Carver, C. S., and Scheier, M. F. (1996). Self-regulation and its failures. Psychological Inquiry, 7, 32-40.

Carver, C. S., and Scheier, M. F. (1998). On the Self-regulation of Behavior. New York: Cambridge University Press.

Chapman, G. B., and Elstein, A. S. (2000). Cognitive processes and biases in medical decision making. In G. B. Chapman and F. A. Sonnenberg (Eds.), Decision Making in Health Care (pp. 183-210). Cambridge: Cambridge University Press.

Cioffi, D. (1991). Asymmetry of doubt in medical self-diagnosis: The ambiguity of "uncertain wellness". Journal of Personality and Social Psychology, 61, 969-80.

Conner, M., and Norman, P. (Eds.). (1996). Predicting Health Behavior: Research and Practice with Social Cognition Models. Buckingham, UK: Open University Press.

Courneya, K. S., Nigg, C. R., and Estabrooks, P. A. (2000). Relationships among the theory of planned behavior, stages of change, and exercise behavior in older persons 
over a three year period. In P. Norman, C. Abraham, and M. Conner (Eds.), Understanding and Changing Health Behavior (pp. 189-206). Amsterdam: Harwood Academic Publishers.

Covello, V. T. (1992). Risk communication: An emerging area of health communication research. In S. A. Deetz (Ed.), Communication Yearbook (Vol. 15, pp. 359-73). Newbury Park, CA: Sage.

Croyle, R. T. (1990). Biased appraisal of high blood pressure. Preventive Medicine, 19, 40-4.

Croyle, R. T., and Sande, G. N. (1988). Denial and confirmatory search: Paradoxical consequences of medical diagnosis. Journal of Applied Social Psychology, 18, 473-90.

Croyle, R. T., Sun, Y. C., and Hart, M. (1997). Processing risk factor information: Defensive biases in health-related judgments and memory. In K. J. Petrie, and J. A. Weinman (Eds.), Perceptions of Health and Illness: Current Research and Applications (pp. 267-90). Singapore: Harwood Academic Publishers.

Croyle, R. T., Sun, Y. C., and Louie, D. H. (1993). Psychological minimization of cholesterol test results: Moderators of appraisal in college students and community residents. Health Psychology, I2, 1-5.

DiClemente, C. C., and Prochaska, J. O. (1982). Self-change and therapy change of smoking behavior: A comparison of processes of change in cessation and maintenance. Addictive Behaviors, 7, 133-42.

Dijkstra, A., and De Vries, H. (2000). Self-efficacy expectations with regard to different tasks in smoking cessation. Psychology and Health, 15, 501-1 1.

Ditto, P. H., and Croyle, R. T. (1995). Understanding the impact of risk factor test results: Insights from a basic research program. In R. T. Croyle (Ed.), Psychological Effects of Screening for Disease Prevention and Detection (pp. 144-81). New York: Oxford University Press.

Ditto, P. H., Jemmott, J. B. III, and Darley, J. M. (1988). Appraising the threat of illness: A mental representational approach. Health Psychology, 7, 183-201.

Fortmann, S. P., Taylor, C. B., Flora, J. A., and Winkleby, M. A. (1993). Effects of community health education on plasma cholesterol levels and diet: The Stanford Five-City Project. American Journal of Epidemiology. I37, 1039-55.

Frank, E., Winkleby, M., Fortmann, S., and Farquhar, J. W. (1993). Cardiovascular disease risk factors: Improvements in knowledge and behavior in the 1980s. American Journal of Public Health, 83, 590-3.

Godin, G., and Kok, G. (1996). The theory of planned behavior: A review of its applications to health-related behaviors. American Journal of Health Promotion, 11, 87-97.

Gollwitzer, P. M. (1999). Implementation intentions: Strong effects of simple plans. American Psychologist, 54, 493-503.

Gollwitzer, P. M., and Oettingen, G. (2000). The emergence and implementation of health goals. In P. Norman, C. Abraham, and M. Conner (Eds.), Understanding and Changing Health Behavior (pp. 229-60). Amsterdam; Harwood Academic Publishers.

Hahn, A., and Renner, B. (1998). Perception of health risks: How smoker status affects defensive optimism. Anxiety, Stress, and Coping, I I, 93-112.

Hermand, D., Mullet, E., and Lavieville, S. (1997). Perception of the combined effects of smoking and alcohol on cancer risks in never smokers and heavy smokers. Journal of Health Psychology, 2, 481-91.

Herzog, T. A., Abrams, D. B., Emmons, K. M., Linnan, L. A., and Shadel, W. G. (1999). Do processes of change predict smoking stage movements? A prospective analysis of the transtheoretical model. Health Psychology, 18, 369-75.

Jeffery, R. W., French, S. A., and Rothman, A. J. (1999). Stage of change as a predictor of success in weight control in adult women. Health Psychology, 18, 543-6. 
Jemmott, J. B., Ditto, P. H., and Croyle, R. T. (1986). Judging health status: Effects of perceived prevalence and personal relevance. Journal of Personality and Social Psycho. logy, 50, 899-905.

Jimison, H. B., and Sher, P. (2000). Advances in presenting health information to patients. In G. B. Chapman and F. A. Sonnenberg (Eds.), Decision Making in Health Care (pp. 334-61). Cambridge, England: Cambridge University Press.

Kraft, P., Sutton, S. R., and McCreath-Reynolds, H. (1999). The transtheoretical model of behaviour change: Are the stages qualitatively different? Psychology and Health, 14. 433-50.

Lachendro, E., and Weinstein, N. D. (1982). Egocentrism as a source of unrealistic optimism. Personality and Social Psychology Bulletin, 8, 195-200.

Lichtenstein, S., Slovic, P., Fischhoff, B., Layman, M., and Combs, B. (1978). Judged frequency of lethal events. Journal of Experimental Psychology: Human Learning and Memory, 4, 551-78.

Linville, P. W., Fischer, G. W., and Fischhoff, B. (1993). AIDS risk perceptions and decision biases. In J. B. Pryor and G. D. Reeder (Eds.), The Social Psychology of HIV Infection (pp. 5-38). Hillsdale, NJ: Erlbaum.

Marlatt, G. A., Baer, J. S., and Quigley, L. A. (1995). Self-efficacy and addictive behavior. In A. Bandura (Ed.), Self-efficacy in Changing Societies (pp. 289-315). New York: Cambridge University Press.

McCaul, K. D., Thiesse-Duffy, E., and Wilson, P. (1992). Coping with medical diagnosis: The effects of at-risk versus disease labels over time. Journal of Applied Social Psychology. 22, 1340-55.

Niknian, M., Lefebvre, R. C., and Carleton, R. A. (1991). Are people more health conscious? A longitudinal study of one community. American Journal of Public Health, 81, 203-5.

OIdenburg, B., Glanz, K., and French, M. (1999). The application of staging models to the understanding of health behaviour change and the promotion of health. Psychology and Health, 14, 503-16.

Perloff, L. S., and Fetzer, B. K. (1986). Self-other judgments and perceived vulnerability to victimization. Journal of Personality and Social Psychology, 50, 502-10.

Prochaska, J. O., DiClemente, C. C., and Norcross, J. C. (1992). In the search of how people change: Applications to addictive behaviors. American Psychologist, 47, $1102-$ 14.

Prochaska, J. O., Johnson, S., and Lee, P. (1998). The transtheoretical model of behavior change. In S. A. Shumacker, E. B. Schron, J. K. Ockene, and W. L. McBee (Eds.), The Handbook of Health Behavior Change (pp. 59-84). New York: Springer.

Prochaska, J. O., Velicer, W. F., Rossi, J. S. et al. (1994). Stages of change and decisional balance for 12 problem behaviors. Health Psychology, 13, 39-46.

Quinlan, K. B., and McCaul, K. D. (2000). Matched and mismatched interventions with young adult smokers: Testing a stage theory. Health Psychology, 19, 16571.

Renner, B. (2001). Health behavior assessment. In N. J. Smelser and P. B. Baites (Eds.), The International Encyclopedia of the Social and Behavioral Sciences (Vol. 10. pp. 6512-15). Oxford, England: Elsevier.

Renner, B., Knoll, N., and Schwarzer, R. (2000). Age and body weight make a difference in optimistic health beliefs and nutrition behaviors. International Journal of Behavioral Medicine, 7, 143-59.

Robert Koch Institut (2000). Sexuelles Risikoverhalten bei homosexuellen Männern in Deutschland [Sexual risk behavior among gay men in Germany]. Epidemiologisches Bulletin, 48, 379-86. 
Sastre, M. T. M., Mullet, E., and Sorum, P. C. (1999). Relationship between cigarette dose and perceived risk of lung cancer. Preventive Medicine: An International Journal Devoted to Practice and Theory, 28, 566-71.

Schneiderman, L. J., and Kaplan, R. M. (1992). Fear of dying and HIV infection vs. hepatitis B infection. American Journal of Public Health, 82, 584-6.

Schwarzer, R. (1992). Self-efficacy in the adoption and maintenance of health behaviors: Theoretical approaches and a new model. In Schwarzer, R. (Ed.), Self-efficacy: Thought Control of Action (pp. 217-43). Washington, DC: Hemisphere.

Schwarzer, R. (1994). Optimism, vulnerability, and self-beliefs as health-related cognitions: A systematic overview. Psychology and Health, 9, 161-80.

Schwarzer, R. (1999). Self-regulatory processes in the adoption and maintenance of health behaviors. The role of optimism, goals, and threats. Journal of Health Psycho. logy, 4, I1 5-27.

Schwarzer, R., and Fuchs, R. (1995). Changing risk behaviors and adopting health behaviors: The role of self-efficacy beliefs. In A. Bandura (Ed.), Self-efficacy in Changing Societies (pp. 259-88). New York: Cambridge University Press.

Schwarzer, R., and Fuchs, R. (1996). Self-efficacy and health behaviors. In M. Conner and P. Norman (Eds.), Predicting Health Behaviour: Research and Practice with Social Cognition Models (pp. 163-96). Buckingham, UK: Open University Press.

Schwarzer, R., and Renner, B. (2000). Social-cognitive predictors of health behavior: Action self-efficacy and coping self-efficacy, Health Psychology, 19, 487-95.

Shaklee, H., and Fischhoff, B. (1990). The psychology of contraceptive surprises: Cumulative risk and contraceptive effectiveness. Journal of Applied Social Psychology, 20, $385-403$.

Sheeran, P., and Orbell, S. (2000). Using implementation intentions to increase attendance for cervical cancer screening. Health Psychology, 19, 283-9.

Siegrist, M., and Cvetkovich, G. (2000). Perceptions of hazards: The role of trust and knowledge. Risk Analysis, 20, 713-19.

Slovic, P., Fischhoff, B., and Lichtenstein, S. (1987). Behavioral decision theory perspectives on protective behavior. In N. D. Weinstein (Ed.), Taking Care: Understanding and Encouraging Self-protective Behavior (pp. 14-41). Cambridge, England: Cambridge University Press.

Strecher, V. J., and Kreuter, M. W. (1995). The psychological and behavioral impact of health risk appraisals. In R. T. Croyle (Ed.), Psychological Effects of Screening for Disease Prevention and Detection (pp. 126-43). New York: Oxford University Press.

Suls, J., and Wheeler, L. (2000). Handbook of Social Comparison. New York: Kluwer.

Sutton, S. R. (2000). A critical review of the transtheoretical model applied to smoking cessation. In P. Norman, C. Abraham, and M. Conner (Eds.), Understanding and Changing Health Behavior (pp. 207-25). Amsterdam: Harwood Academic Publishers.

Sutton, S. R. (2001). Health behavior, psychosocial theories of. In N. J. Smelser and P. B. Baltes (Eds.). The International Encyclopedia of the Social and Behavioral Sciences (Vol. 10, pp. 6499-6506). Oxford, England: Elsevier.

Taylor, K. M., and Shepperd, J. A. (1998). Bracing for the worst: Severity, testing, and feedback timing as moderators of the optimistic bias. Personality and Social Psychology Bulletin, 24, 915-26.

Taylor, S. E., Pham, L. B., Rivkin, I. D., and Armor, D. A. (1998). Harnessing the imagination: Mental stimulation, self-regulation, and coping. American Psychologist, 53, 429-39.

Thompson, S. C., Anderson, K., Freedman, D., and Swan, J. (1996). Illusions of safety in a risky world: A study of college students' condom use. Journal of Applied Social Psychology, 26, 189-210. 
Velicer, W. F., DiClemente, C. C., Prochaska, J. O., and Brandenburg, N. (1985). Decisional balance measure for assessing and predicting smoking status. Journal of Personality and Social Psychology, 48, 1279-89.

Wallston, K. A. (2001). Control beliefs. In N. J. Smelser and P. B. Baltes (Eds.), The International Encyclopedia of the Social and Behavioral Sciences (Vol. 10, pp. 2724-26). Oxford, England: Elsevier.

Wallston, K., and Armstrong, C. (2002). Theoretically-based strategies for health behavior change. In M. P. O'Donnell (Ed.), Health Promotion in the Workplace (3rd edn., pp. 182-201). Albany, NY: Delmar.

Weinstein, N. D. (1980). Unrealistic optimism about future life events. Journal of Personality and Social Psychology, 39, 806-20.

Weinstein, N. D. (1988). The precaution adoption process. Health Psychology, 7, 355-86. Weinstein, N. D. (1993). Testing four competing theories of health-protective behavior.

Health Psychology, 12, 324-33.

Weinstein, N. D. (1998). Accuracy of smokers' risk perceptions. Annals of Behavioral Medicine, 20, 135-40.

Weinstein, N. D. (2000). Perceived probability, perceived severity, and healthprotective behavior. Health Psychology, 19, 65-74.

Weinstein, N. D., and Klein, W. M. (1995). Resistance of personal risk perceptions to debiasing interventions. Health Psychology, 14, 132-40.

Weinstein, N. D., Lyon, J. E., Sandman, P. M., and Cuite, C. L. (1998a). Experimental evidence for stages of health behavior change: The precaution adoption process model applied to home radon testing. Health Psychology, 17, 445-53.

Weinstein, N. D., Rothman, A. J., and Sutton, S. R. (1998b). Stage theories of health behavior: Conceptual and methodological issues, Health Psychology, 17, 290-9.

Weinstein, N. D., and Sandman, P. M. (1992). A model of the precaution adoption process: Evidence from home radon testing. Health Psychology, 11, 170-80.

Whitley, B. E., and Hern, A. L. (1991). Perceptions of vulnerability to pregnancy and the use of effective contraception. Personality and Social Psychology Bulletin, 17. 104-10.

Winders, S. E., Kohler, C. L., Grimley, D. M., and Gallagher, E. A. (1999). Tobacco use prevention and cessation. In J. M. Raczynski and R. J. DiClemente (Eds.), Handbook of Health Promotion and Disease Prevention. (pp. 149-69). New York: Kluwer Academic Plenum Publishers.

Yates, J. F. (Ed.). (1992). Risk-taking Behavior. New York: Wiley. 